\title{
Substitute for the Breast Milk (Sale, Distribution and Control) Act 2049.
}

- NEPAL GAZETTE (Translated Version in English).

- Published by Nepal Government (the then HMG). Volume 42. Kathmandu. 29 ${ }^{\text {th }}$ Mangshir 2049 (Supplementary 48). An Act Made to Control the Sale and Distribution of Breast milk Substitute. Act No. 39 of 2049 (1992A.D.)

\section{The act passed to regulate the sale and distribution of substitute for the Brest Milk}

Preamble: As it has become necessary to patronize and promote Breast Feeding and regulate the sale and distribution of substitute for breast milk including infant feed: The Parliament has made this Act in the twenty first year of His Late Majesty King Birendra Bir Bikram Shah Dev's Regime.

\section{Clause 1. Short Title and Commencement:}

Section 1.01 This Act has been named "Substitute for the Breast Milk (Sale, Distribution and Control) Act 2049".

Section 1.02 This Act shall come into force on such date as Nepal Government may specify by publishing notification in Nepal Gazette.

\section{Clause 2. Definition:}

Unless the subject or context defines otherwise, in this Act:

Section 2.01 "Substitute for the Breast Milk" Means an edible product that is sold and distributed to partially or fully substitute the Breast Milk.

Section 2.02 "Container" denotes the pouch or package that is used to sell the product in retail and this word also denotes the wrappers of the product.

Section 2.03 "Committee" means the Breast Feeding Protection and promotion committee formed in accordance with Clause 4.

Section 2.04 "Product" denotes the following commodities:

(a) Commodity that substitutes the Breast Milk.

(b) Any type of milk that is suitable to feed the infant with some or without changes.

(c) Any other food or drink sold or distributed that is suitable to feed the infant.

(d) Feeding Bottle and Nipple.

Section 2.05 "Distributor" means a person connected with the sale and distribution of the product in wholesale or retail and this term also denotes the person who is involved in product related public relations or information providing job.

Section 2.06 "Health Care Agency" means Government, Non Government or private institution or organization or a person that are directly or indirectly related to the work of health care and this term also denotes the Nurseries and other Child care institutions.

Section 2.07 "Health worker" means a person who is working in health care Agencies or receiving training to work or unpaid person working in Health care Agencies.

Section 2.08 "Child" means a child up to the age of 12 months.

Section 2.09 "Infant Formula" means a substitute feed of Breast Milk produced as per the current Nepalese standard for the infants of four to six months age with the objective of fulfilling the required general nutrition of the infants and suitable to physical composition of such infants.

Section 2.10 "Label" Means the written, printed, lithographed, marked, embossed, enclosed or others shown in the form of the tag, symbol, photo or other descriptive items on the container containing the product.

Section 2.11 "Manufacturer" means the person involved in the activity of manufacturing or producing directly or through agent or by means of Agreement or through a person bonded by the Agreement.

Section 2.12 "Sale and Distribution" means the promotion, distribution, advertisement, sample distribution, public relation and information service of the product including marketing or selling of such products.

Section 2.13 "Sample" means one product or small quantity of the product that is provided free of cost.

Section 2.14 "Complementary food" means a suitable food that can be used as a complementary food in case the infant's nutritional requirements aren't adequately fulfilled by Breast Milk or the substitute Breast Milk.

Section 2.15 "Ministry" means the Ministry of Health of Nepal Government.

Section 2.16 "Prescribed" or "As prescribed" means prescribed or as prescribed in the rule framed under this Act. 
Clause 3. Implementation and supervision:

Section 3.01 The main responsibility of bringing this Act in force and implementing it will be of the Ministry.

Section 3.02 The Ministry can ask for the help of other Ministries as per the requirements to ensure the implementation of this Act.

Section 3.03 The Ministry will have following functions and right in order to implement this Act:

(a) Issuance of rules to implement this Act.

(b) Consultation with Government and Non-Government Agencies to ensure the implementation and full compliance of this Act and the provisions of the rules issued under this Act.

(c) Enforcement of this Act.

(d) To perform required or related other works to achieve the objectives of this Act.

\section{Clause 4. Breast Feeding protection and promotion committee:}

Section 4.01 Nepal Government shall constitute a Breast Feeding protection and promotion Committee to supervise the compliance of this Act and to protect and promote Breast Feeding and regulation the sale and distribution of products.

Section 4.02 The committee shall consists of following members:
(a) The Secretary, Ministry of Health
- Chairman
(b) Representative (Gazetted Ist Class) Ministry of Industry
- Member
(c) Representative (Gazetted Ist Class) Ministry of Supplies
- Member
(d) Representative ( Gazetted Ist Class) Ministry of Commerce
- Member
(e) Representative (Gazetted Ist Class) Ministry of Education and Culture
- Member
(g) Representative (Gazetted Ist Class) Ministry of Labour and Social Welfare
- Member
(h) Representative, Nepal Pediatric Association
- Member
(i) Representative, Federation of Nepal Industries and Commerce
- Member
(j) Two persons nominated by the committee from among the distinguished person working in the field of Mother and Child Health Sector
- Member.
(k) Distinguished Nutritionist nominated by Nepal Government
- Member.
(1) One person nominate by Nepal Government from among the mothers having experience in the field of Children's growth and care
- Member
(m) Person nominated by Nepal Government
- Member Secretary.

Section 4.03 Nominated members shall have the tenure of two years and they can be re-nominated as per the decision of the Committee.

Section 4.04 The Committee can invite national or foreign specialist as an observer in the meetings.

Section 4.05 Nepal Government may increase or decrease the number of members or make alterations by publishing notification in the Nepal Gazette.

\section{Clause 5. Meeting of the Committee.}

Section 5.01 Meeting of the Committee shall be called by the member- secretary on the direction of the Chairman.

Section 5.02 Attendance of two- third members will constitute chorum for a meeting.

Section 5.03 The view of the majority member, present in the meeting, on the subjects presented before the committee's Meeting, shall be treated as the decision of the committee.

Section 5.04 Committee's decision shall be certified by the Member - Secretary.

Section 5.05 Other procedures regarding the Committee's Meeting shall be as determined by the committee itself.

\section{Clause 6. Functions, Duties and powers of the Committee:}

Functions, Duties and powers of the committee shall be as given below under the approved policy of Nepal Government;

a) To supervise whether the Act is complied with or not as prescribed.

b) To recommend investigating and registering case against the manufactures, distributors or Health workers who are found violating the provisions of this Act.

c) To consider the request for receiving any product as a grant and to accept or reject such requests as prescribed.

d) To consider the requests by the Health Workers to receive research scholarships, to participate in business seminars or 
seek help to organize such seminars from the manufactures or distributors and to accept or reject such requests as prescribed.

e) To review the labels of the products presented by Manufacturers and Distributors and to approve the labels that are in conformity with the provisions of this Act.

f) To coordinate the information about infant food and the publicity of educational materials.

g) To draft a National Policy for the protection and promotion of Breast Feeding.

h) To form Sub-Committees as per requirements for implementation, supervision and control.

\section{Clause 7. Information and Education about Infant Food:}

Section 7.01 The Ministry, in consultation with the Committee, shall give permission to publicize the information and educational materials about infant food.

Section 7.02 The written, audible or visual information and educational materials about infant food must provide clear information on following points.

a) Benefits and features of Breast Feeding.

b) Development of Breast milk and maintenance of standard including mother's nutrition.

c) Negative effects of bottle feeding or complementary feed on Breast Feeding.

d) Problem in Breast Feeding after an infant is fed by bottle for sometime.

Section 7.03 The information and the educational materials that includes the feeding of complementary food or substitute for breast milk should also clearly mention following points in addition to information mentioned in Sub- Clause (2):

a) Appropriate use of substitute for Breast milk.

b) The cost involved in feeding the infant with substitute breast milk in comparison to Breast Feeding.

c) The bad effects on health by feeding ill-prepared substitute breast milk and inappropriate food bottle feeding.

d) The method of feeding infants with bowl and spoon.

e) The method of preparing complementary food at home.

Section 7.04 The information and educational materials must have correct and recognized information only and there shouldn't be any photograph or statement that discourages the breast-feeding or promotes the habit of bottle-feeding.

Clause 8. Health Care Agencies and Health Worker:

Section 8.01 The heads of Health Care Agencies, and National and Local health Officers should take appropriate measure in promoting the principles of this Act and in protecting and promoting breast feeding and they should impart appropriate information and advice to Health workers about their responsibilities, and the Health worker must be informed about the matters that is mentioned in clause (7).

Section 8.02 The Health workers have to protect, promote and encourage breast-feeding. They must have the knowledge about the provisions of this Act especially the matters mentioned in clause 7 and have to implement these provisions as far as possible.

Section 8.03 The Health Workers, directly or indirectly, shouldn't do anything to impede the beginning and expansion of breast feeding.

Section 8.04 The Health workers shouldn't accept any financial or material gifts from Manufacturers or Distributors.

Section 8.05 The Health Workers shouldn't provide the samples of any product to anyone.

Section 8.06 The health workers shouldn't in any manner promote the product.

Section 8.07 If any Manufacturer or Distributor seeks to give any gift or other monetary benefits to Health worker should report about it in writing to his/ her agency's Head and the Head too should inform the committee as soon as possible.

\section{Clause 9. Don'ts by the Manufacturer and Distributor:}

Section 9.01 The Manufacturer and the Distributor should not advertise in the following manner

a) In a manner to promote any product.

b) In a manner to state or make believe that bottle-feeding is equal to or better than breast-feeding.

Section 9.02 The Advertisement for the purpose of this clause denotes all advertisements as given below:

a) By any publication or by Television, Radio, Film, Video or Telephone.

b) By Symbol, Bill Board, information or exhibition of the materials.

c) By exhibition of photographs or images.

d) By any other method.

Section 9.03 Notwithstanding any thing written in sub-Clause (1), the publications meant only for the Health professionals can have advertisements of products. But such advertisements must be limited to facts and scientific matters and they shouldn't be in the manner, which seeks to believe that bottle-feeding is equal to or better than better that breastfeeding and such advertisements must have the information mentioned in Clause 7. 
Section 9.04 The Manufacturer or the Distributor shouldn't provide or distribute the samples of the product to anyone.

Section 9.05 The manufacturer or the Distributor shouldn't promote any product in the premises of Health Care Agency

Section 9.06 For the purpose of this Clause "Promotion" means to introduce the product to any person or introducing the person with the product including following methods:

(a) By advertising

(b) By using the printed materials including the name of the proprietary product, logo, graphic or books, pamphlets or posters containing other images.

(c) By giving or distributing any material containing the name of the Manufacturer or the Distributor or logo or name of the proprietary product, logo, graphic or any other images in nominal cost or free.

(d) By exhibiting products and,

(e) By any other methods

Section 9.07 The Manufacturer or the Distributor shouldn't make available the product in lower price than the retail price or shouldn't donate to Health Care Agency or any other institution or organization except in case the health Care Agency or any other institution or organization seeks the grant in prescribed manner and such demand is accepted by the committee as prescribed.

Section 9.08 The manufacturer or the Distributor shouldn't make contact with the general public in the the premises of Health Care Agency in order to enhance their business or such objectives.

Section 9.09 The Manufacturer or the Distributor shouldn't donate any equipment or materials to health Care Agent without taking the permission of the committee.

Section 9.10 The Manufacturer or the Distributor shouldn't give any gift or provide monetary or other benefits to the Health worker.

Section 9.11 Unless the Manufacturer or the Distributor or the Health worker requests on prescribed manner and such request is approved by the committee as prescribed, the health worker shouldn't be given scholarship or research grant or the amount requires to organize business seminar or meeting or needed by the health worker to participate in such meeting.

\section{Clause 10. Certification of the product:}

Section 10.01 Section The manufacturer or the Distributor has to obtain the certification from central food research Laboratory before selling their product in Nepal except for feeding bottle and nipple.

Section 10.02 In case of a product already on sale in Nepal, the Manufacturer or the Distributor has to obtain the certification from the central food research Laboratory within ninety days of this Act's enforcement.

Section 10.03 For the purpose of sub-Clause (1) and (2), the manufacturer or the Distributor should apply in a prescribed from along with the sample of the product and requisite fees to Central Food Research Laboratory.

\section{Clause 11. Labeling of products:}

Section 11.01 The Manufacturer or the Distributor should apply in a prescribed from along with the sample of the product and requisite fees to the committee for approval of the labels of such products before selling it in Nepal.

Section 11.02 If the product is already in Nepal for sale the Manufacturer or the Distributor should apply to the committee for approval of labels of such products within 90 days of the enforcement of this Act.

Section 11.03 Label of the product must be designed in such a way that it should provide necessary information on the method of its use and it mustn't discourage breast-feeding.

Section 11.04 There shouldn't be any photo, map or any other images on the label of the product or container except the graphic that explains the method of preparing it.

Section 11.05 Name and address of Manufacturer and if possible Distributor should be on the label of the product.

Section 11.06 The container or irremovable label of the substitute product for breast milk or other milk products that comes under the purview of this Act and the label which can't be in a language clearly and should be intelligible and easily comprehensible;

a) Important Notice or similar words.

b) The statement that the breast milk is best for baby.

c) Regarding the need and method of use, there should be a statement that this product shouldn't be used without the advice of Health Worker.

d) Easily comprehensible appropriate directions and graphics to prepare the baby food, and.

e) The quantity of the substitute product or any other milk product of breast milk for each month should be mentioned.

Section 11.07 The words like humanized or materialized or any similar words shouldn't be used. 
Section 11.08 The unalterable label or the product kept in a transparent container should mention that the infant formula is not the sole source of nourishment to the infants and there should also be caution that the product must not be fed to infants without the directions of Health Worker.

Section 11.09 There should be a clear and legible caution in the label of the Sweetened condensed milk that this shouldn't be used for infant feeding.

Section 11.10 The following matters should be mentioned on the labels of all products except feeding bottle and nipple.

(a) Users (Meant for)

(b) Analysis and Composition of the product.

(c) Conditions to be followed while storing.

(d) Batch No. Storage Conditions, Date of manufacture and date of Expiry keeping in view the weather conditions.

Section 11.11 The Name and the Address of the Manufacturer and Distributor should be mentioned on the feeding bottle and the nipple along with the message that Breast Milk is the best for infants and it should be fed using bowl and spoon instead of feeding bottle.

Clause 12 Quality:

Section 12.01 While manufacturing, selling or distributing in other ways, the products should be of the standard quality prescribed or recommended by the Nepal Quality Standard Office.

Section 12.02 Central Food Research laboratory will have the rights to test any product sold in Nepal to ascertain whether the product is fit for human consumption or not.

Section 12.03 The products that do not meet the quality standards in the producing country will not be allowed to be sold in Nepal.

Section 12.04 The product, which is beyond the Date of Expiry, should not be bought in the market or distributed.

Section 12.05 All other products except feeding bottle and nipple must be sold in the original container so that the quality of the product can be maintained and it can be protected from adulteration and pollution.

\section{Clause 13. Monitoring:}

Section 13.01 The Ministry, on the recommendations of the Committee that was formed to monitor and investigate the compliance of this Act or the rules framed under this Act by Manufacturers, Distributors, Monitoring, Agencies and Health Workers can appoint Monitors as per the requirements or Government employees can be deputed to work as monitors after obtaining the approval of the concerned departments of Nepal Government.

Section 13.02 The appointed or deputed Monitors under Sub-clause (1) will have to monitor and investigate as directed whether the Manufacturers, Distributors, Health Monitoring Agencies and Health Workers are complying with this Act or the rules formed under this Act or not and submit their reports to the committee.

\section{Clause 14. Suspension or Termination or License, Permit or Authority Letter:}

As per the sub- Clause (2) of Clause 13, if any Manufacturer, Distributor, health Monitoring Agency or health Worker is found violating this Act or the rules framed under this Act in the reports, submitted by the Monitors, the Ministry, on the recommendations of the Committee, can write to concerned Department to suspend or cancel the License, permit or Authority letter given by Nepal Government or any other Department to carry their business or trade.

\section{Clause 15. Duties and the Rights of Monitor:}

Monitors will be having other directed duties and rights apart from the duties and rights mentioned in this Act.

\section{Clause 16. Penalty and Punishment:}

Section 16.01 The health worker who violates the Sub- Clause (4),(5) or (6) of Clause 8 has to pay up to Rupees One Thousand Only as a penalty or undergo a month's imprisonment or both.

Section 16.02 The manufacturer or the Distributor who violates Sub- Clause (1), (4), (5), (7), (8), (9) (10) or (11) of Clause 9 has to pay up to Rupees Ten Thousand Only as a penalty or undergo three month's imprisonment or both.

Section 16.03 The manufacturer or the distributor violating Clause 10 or 11 has to pay up to Rupees Two Thousand as a penalty or undergo one month's imprisonment or both.

Section 16.04 The person who violates other provisions of this Act or the rules framed under this Act except mentioned in the Sub- Clause (1), (2) or (3) has to pay up to Rupees Two Thousand as a penalty or undergo one month's imprisonment or both keeping in view the nature of their offence.

Section 16.05 The court, wile dispensing the Judgment under this Clause, can order the offender to pay the affected person or his/ her heir Rupees Two Thousand Five hundred up to Rupees One Lac as compensation. 
Clause 17. The Responsibility of the Firm or Organized Institution: If any Firm or Organized Institution violates this Act or the rules framed under this Act such firm's owner or partner and Chief Administrative officer, who executes the work, of Organized Institution, shall be liable for punishment under Clause 16.

\section{Clause 18. Government as plaintiff:}

Nepal Government shall be the plaintiff in the cases under this Act.

\section{Clause 19. Investigation and Registration of the Case:}

Section 19.01 The offences that can be tried under this Act will be in investigated by the Monitor and, after completion of such investigation or investigation work: case will be registered in the District Court.

Section 19.02 The Monitor, while registering the Case under Sub-Clause (1), Can consult the public Prosecutor. The Public Prosecutor will fight the case after registration of the case.

\section{Clause 20. Right to frame the Rules:}

Nepal Government can make necessary rules to implement the objectives of this Act.

Stamped dated: 2049/8/29/2 (Monday the $14^{\text {th }}$ December 1992)

By Order

Vedvyas Chhetri

Secretary to the then His Majesty's Government. 